
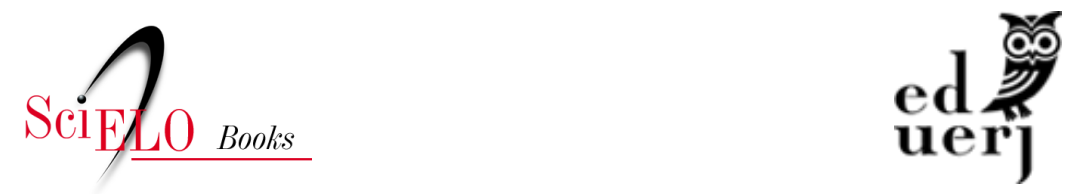

\title{
Os desafios à consolidação de uma rede federal de educação profissional, científica e tecnológica no Brasil
}

\author{
Linovaldo Miranda Lemos \\ Rafael Straforini \\ Gustavo Teramatsu
}

\section{SciELO Books / SciELO Livros / SciELO Libros}

LEMOS, L. M., STRAFORINI, R., and TERAMATSU, G. Os desafios à consolidação de uma rede federal de educação profissional, científica e tecnológica no Brasil. In: MAIA, D. S., and MARAFON, G. J., eds. Ensino superior e desenvolvimento regional: reconfigurando as relações entre as cidades e o campo [online]. Rio de Janeiro: EDUERJ, 2020, pp. 235-260. ISBN: 978-65-87949-08-6.

https://doi.org/10.7476/9786587949086.0009.

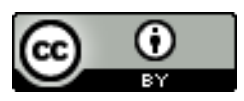

All the contents of this work, except where otherwise noted, is licensed under a Creative Commons Attribution 4.0 International license.

Todo o conteúdo deste trabalho, exceto quando houver ressalva, é publicado sob a licença Creative Commons Atribição 4.0.

Todo el contenido de esta obra, excepto donde se indique lo contrario, está bajo licencia de la licencia Creative Commons Reconocimento 4.0. 


\section{Os DESAFIOS À CONSOLIDAÇÃO DE UMA REDE FEDERAL DE EDUCAÇÃO PROFISSIONAL, CIENTÍFICA E TECNOLÓGICA NO BRASIL}

Linovaldo Miranda Lemos

Rafael Straforini

Gustavo Teramatsu

\section{Introdução}

O conjunto das centenárias instituições federais dedicadas ao ensino profissional de base técnica assistiu, nas duas últimas décadas, a uma série de movimentos que a transformaram significativamente. A ampliação, tanto do número de unidades quanto da cobertura geográfica da Rede Federal de Educação Profissional, Científica e Tecnológica (RFEPCT), se deu concomitantemente ao aumento, também, do seu raio e do seu escopo de atuação e da oferta de diversas modalidades de cursos e em diferentes níveis de ensino. Para além desses fatos, assistiu-se, também, à criação de uma nova arquitetura institucional, visando dar conta dos desafios e das demandas sociais e governamentais, progressivamente assumidos por essas instituições. Entre essas atribuições, está a formação de professores, objeto principal desse artigo.

Procuramos trazer elementos que visam contribuir ao estabelecimento de um perfil das licenciaturas ofertadas nos Institutos no 
que se refere à identificação dos cursos existentes e à sua distribuição no território nacional. Nesse sentido, responde primordialmente a quais cursos e em que locais eles são ofertados pela rede, identificando-os nominalmente, quantificando-os em relação a cada campus e em relação ao conjun to da rede e verificando a sua distribuição entre as regiões brasileiras. Para tanto, lançou mão da pesquisa documental em fontes primárias, como documentos oficiais; dados do Censo da Educação Superior e pesquisas nos sites de cada um das unidades dos 38 Institutos Federais, além de pesquisa realizada junto à Plataforma Nilo Peçanha (https://www.plataformanilopecanha.org/) recentemente lançada pela rede. Apresentam-se os resultados sob a forma de gráficos e tabelas, procedendo-se às análises consideradas pertinentes e fazendo dialogar esses dados com a bibliografia sobre o tema. O texto visa contribuir com elementos para o estabelecimento de parâmetros capazes de melhor compreender a abrangência das licenciaturas no contexto da RFEPCT, o que pressupõe dizer que outros elementos são necessários, ainda, para uma visão mais pormenorizada de tal oferta.

\section{A constituição da Rede Federal de Educação Profissional, Científica e Tecnológica}

[... o aumento constante da população das cidades exige que se facilite às classes proletárias os meios de vencer as dificuldades sempre crescentes da luta pela existência; que para isso se torna necessário, não só habilitar os filhos dos desfavorecidos da fortuna com o indispensável preparo técnico e intelectual, como fazê-los adquirir hábitos de trabalho profícuo, que os afastará da ociosidade, escola do vício e do crime; que é um dos primeiros deveres do Governo da República formar cidadãos úteis à Nação (Brasil, 1909).

A criação das "Escolas de Aprendizes e Artífices”, em 1909, é considerada o marco fundador da educação profissional no Bra- 
sil. No documento de sua criação explicitava-se a compreensão da necessidade de se oferecer aos "desfavorecidos da fortuna" algum tipo de conhecimento técnico que se traduzisse na formação de “operários e de contramestres em ofícios que envolviam o conhecimento técnico e prático com o trabalho em madeira, metal e arte decorativa" (Soares, 1982). Ao afastar a população pobre "da ociosidade ignorante, escola do vício e do crime" - para utilizar-se das palavras do Decreto No 7.566/1909 - o ensino profissional assumia, nesse sentido, uma dupla finalidade: de um lado, oferecer formas de sustento aos indivíduos por meio do trabalho e, por outro, fomentar o "progresso", fornecendo mão de obra especializada, necessária àquele momento histórico de um país recém saído da escravidão (Kunze, 2009).

Entre as décadas de 1910 e 1950, as antigas Escolas de Aprendizes e Artífices passam a se chamar, progressivamente, de "Liceus Industriais" (1916), "Escolas Industriais e Técnicas" (1942) e "Escolas Técnicas Federais" (1959). Acompanhando um processo crescente de urbanização e de industrialização, o conjunto das escolas federais alinhava-se assim, pari passo, às necessidades da economia nacional, especialmente no que se refere à formação de mão de obra para o setor industrial. De uma perspectiva mais ampla, pode-se considerar que a trajetória de constituição histórica da rede esteve ligada ao próprio desenvolvimento do modelo econômico brasileiro ao longo do século XX (Pereira, 2003).

Em 1978, passa a existir uma diferenciação dentro do conjunto das Escolas Técnicas com a transformação das unidades do Rio de Janeiro, Paraná e Minas Gerais em "Centros Federais de Educação Tecnológica” (CEFET), por meio da Lei 6545 (Brasil, 1978). Ao longo do tempo, outras unidades foram progressivamente se transformando em CEFET, como a Escola Técnica Federal do Maranhão, em 1989, e a Escola Técnica Federal da Bahia, em 1993 (Brasil, 1989 e 1993), mas a transformação do conjunto das Escolas em CEFET se dará entre as décadas de 1990 e início dos anos 
2000, a partir da institucionalização de um "Sistema Nacional de Educação Tecnológica” com a Lei n. ${ }^{\circ} 8.948$ (Brasil, 1994; Oliveira, 2003 e Pereira, 2003). A partir de uma autorização anteriormente dada para que essas escolas ministrassem cursos de curta duração em engenharia de operação, a Lei passa a permitir que os CEFET se dedicassem, também, aos cursos em nível superior para a formação de "profissionais e especialistas na área tecnológica", formação de professores voltados especificamente para as áreas técnicas, ao oferecimento de cursos de educação continuada para o aperfeiçoamento na área tecnológica bem como à realização de pesquisas aplicadas.

A base institucional-legal que respalda os cursos de licenciatura especifica como finalidades e características dos Institutos, "qualificar-se como centro de referência no apoio à oferta do ensino de ciências nas instituições públicas de ensino, oferecendo capacitação técnica e atualização pedagógica aos docentes das redes públicas de ensino" (Lei n. ${ }^{\circ} 11.892$, Art. $6^{\circ}$ ). Em consonância com essa finalidade, a legislação prevê ainda, como um dos seus objetivos,

ministrar em nível de educação superior [...] cursos de licenciatura, bem como programas especiais de formação pedagógica, com vistas na formação de professores para a educação básica, sobretudo nas áreas de ciências e matemática, e para a educação profissional" (Art. $\left.7^{\circ}\right)$.

E, visando reforçar esse papel de instituições dedicadas à formação de professores, prescreve-se, ainda, um mínimo de 20\% do quadro de vagas para as licenciaturas. Em outras palavras, formar professores passou a ser não mais uma possibilidade ou uma prerrogativa - assumida por muitos Institutos antes mesmo de 2008 -, mas uma exigência que tornou os Institutos um novo lócus de formação docente.

No que se referem aos objetivos da RFEPCT, expressos na letra da Lei (Brasil, 2008) e assumidos progressivamente às suas 
práticas organizativas e administrativas pelos Institutos, destaca-se a ampla gama de atribuições, competências e prerrogativas previstas. De forma sumária, cabe aos Institutos: a) ministrar educação profissional técnica de nível médio, bem como cursos de formação inicial e continuada de trabalhadores, em todos os níveis de escolaridade, nas áreas da educação profissional e tecnológica; b) realizar pesquisas aplicadas; c) desenvolver atividades de extensão; d) estimular e apoiar processos educativos com vistas à geração de renda; d) promover o desenvolvimento socioeconômico local e regional; e) ministrar, em nível de educação superior, cursos superiores de tecnologia, licenciaturas, programas especiais de formação pedagógica, cursos de bacharelado e engenharia, cursos de pós-graduação lato sensu de aperfeiçoamento e especialização e) cursos de pós-graduação stricto sensu (mestrado e doutorado).

Fugiria ao escopo do artigo discutir cada um desses objetivos. Não obstante, caberia chamar a atenção para os enormes desafios advindos dessa ampla gama de "funções". Por esse motivo, Fartes (2014) considerou os Institutos "um produto híbrido que deve atuar em todos os níveis e modalidades" (p. 851). O "hibridismo" se refere ao fato de que aquelas atribuições mais tradicionais voltadas à formação de profissionais de nível básico e médio se agregaram uma série de outras, que culminaram com um processo de verticalização do ensino de uma ponta a outra do processo educativo (ou seja, da formação no nível mais básico ao doutorado). Essa verticalização pode ser encarada como uma tendência que atende aos interesses do mercado de trabalho (Weinberg, 2004) e da própria dinâmica produtiva (Brasil, 2010), o que traz consigo uma série de desafios para os envolvidos no processo, especialmente para professores e para o corpo técnico-administrativo das instituições (Quevedo, 2016). Não sem motivo, já se ter dito que tal diversidade de atuação de uma instituição pode representar "a riqueza dos IFs [sic] ou sua desgraça (Gouveia e Silva, 2017, p. 11). 
Outro ponto importante a ser considerado é a multiplicidade de programas e ações governamentais nas quais os Institutos estão engajados: o Ministério da Educação (MEC) - via SETEC - foi estruturando uma série de iniciativas a serem executadas pela Rede, o que possibilitou o aprofundamento da presença desse sistema no cenário educacional brasileiro. É nesse contexto que se inserem o Programa Nacional de Acesso ao Ensino Técnico e Emprego (Pronatec) e suas ações de ampliação das vagas e expansão tanto da Rede Federal quanto das Redes Estaduais de educação profissional, o oferecimento de bolsas de estudos aos alunos em formação, bem como o estímulo a educação à distância (Brasil, 2011a); o Programa Mulheres Mil com o oferecimento de cursos profissionalizantes a mulheres em condições de vulnerabilidade social, visando à redução das desigualdades de gênero, a violência contra a mulher e a sua inclusão (Brasil, 2011b).

\section{A distribuição territorial dos Institutos Federais}

Desde meados dos anos 2000, tem havido uma expansão das Universidades e dos Institutos Federais no país, o que se traduziu numa maior presença dessas instituições no território (Freitas et al., 2015). No caso dos Institutos Federais, dados disponibilizados pelo MEC/SETEC e pela Plataforma Nilo Peçanha dão conta de que, entre os anos de 2002 e 2016, houve um salto de 140 para 643 unidades, o que representa um aumento de mais de $500 \%$ no período.

Os gráficos 1 e 2 , dispostos abaixo, procuram traçar um perfil inicial da distribuição dos Institutos pelo território. ${ }^{1}$

\footnotetext{
1 Faz-se necessário uma longa nota explicativa acerca dos instrumentos metodológicos que levaram à construção dos gráficos 1 e 2 e as razões da escolha da Portaria n. ${ }^{\circ} 1.400 / 2016$ como fonte específica de pesquisa. Inicialmente recorreu-se a um trabalho, dir-se-ia, artesanal de busca e identificação dos Institutos, caso a caso, estado por estado, mediante a pesquisa de suas unidades em seus respectivos sites da internet. No entanto, percebeu-se a discrepância nos números encontrados e aqueles disponíveis no site do próprio MEC/SETEC. Procedeu-se ao envio de um
} 


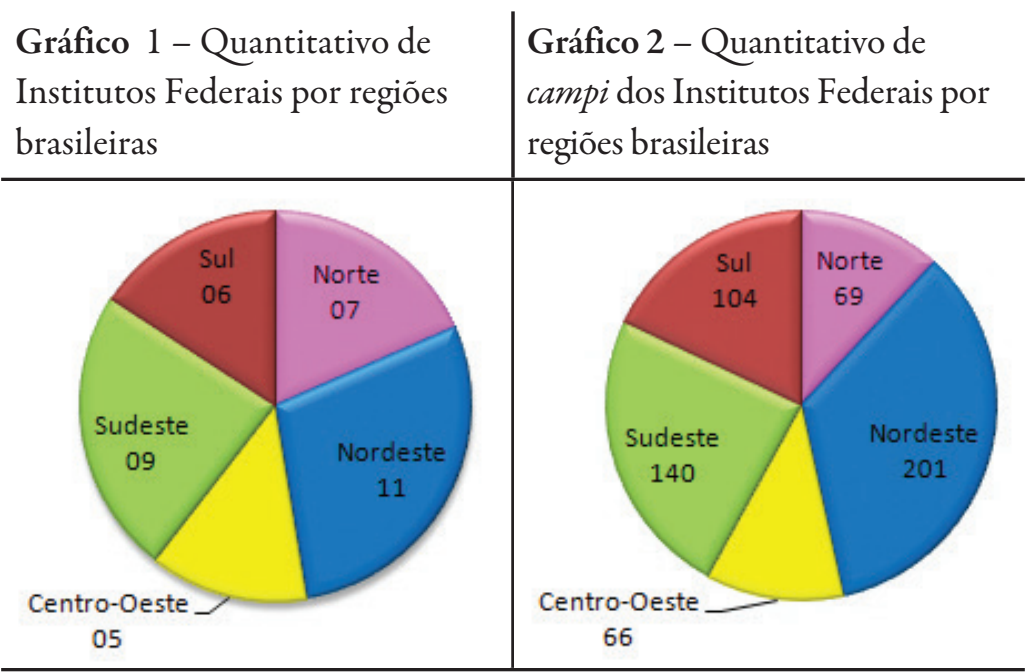

Fonte: Elaboração própria com base na Portaria n. ${ }^{\circ} 1.400$ de 05 de dezembro de 2016 (Brasil, 2016).

No que se refere à distribuição da RFEPCT, conforme se pode observar nos gráficos 1 e 2 , a região Nordeste concentra a maior parte das Instituições da rede (11) bem como do total de

e-mail ao MEC solicitando as informações, o que foi atendido com o forncecimento da referida Portaria. Nesse ínterim, é lançado, em março de 2018, o site da Plataforma Nilo Peçanha. Mais uma vez, a pesquisa encontrou certas discrepâncias nos dados que poderiam ser sintetizados da seguinte forma: a) casos de unidades que só constam no na Plataforma Nilo Peçanha e que não constam na Portaria, na sua maioria, os chamados "Centros de Referência" ligados às atividades de pesquisa e administras; b) inversamente, centros e unidades que só constavam na Portaria e que não estavam dispostos na Plataforma. Procedeu-se, então, consulta ao pessoal do CONIF, responsável pela Plataforma, detalhando, caso a caso, essas inconsistências e solicitando explicações. O CONIF, então, remete os questionamentos à SETEC que, por e-mail, remete a Portaria SETE de 01 de janeiro de 2018 que considera como "unidades de ensino todas as unidades organizacionais [...] que possuem matrículas vinculadas". Dessa forma, continua o e-mail, "todas as unidades de ensino cadastradas no Sistec (e com matrículas ativas em 2017) foram contabilizadas na Plataforma Nilo Peçanha. Trata-se do conceito acadêmico de unidade e não administrativo". A opção consciente nessa pesquisa foi de seguir a Portaria de 2016 do MEC por considerarmos que o foco da pesquisa, nesse momento, é a presença física no território ( e não o critério administrativo adotado pela SETEC. 
campi instalados (201), possuindo, ainda, a segunda e a terceira instituição com o maior número de unidades (Instituto Federal do Ceará e do Maranhão com 31 e 28 unidades, respectivamente).

Aliando-se dados expressos nos gráficos 1 e 2 à análise da bibliografia sobre o tema (Andrade, 2014 e Silva, 2016), chama a atenção o crescimento da Rede para além do Sudeste e Sul do país, regiões tradicionalmente melhor dotadas de equipamentos e instalações de ensino. Destaque pode ser dado à região Norte do país em função de sua tradicional opacidade nesse sentido: até 2005, os estados do Acre e do Amapá não possuíam nenhuma unidade da Rede, ao passo que Rondônia, Roraima e Tocantins contavam somente com uma unidade cada. De 15 institutos em 2005, essa região passa para 66 na última fase da expansão De forma similar, em comparação ao ano de 2002, o Centro-Oeste teve, em 2014, um aumento de 392,3\% no número de unidades da Rede, passando de 11 para 64 no período e chegando, de acordo com os últimos levantamentos expressos no gráfico 2, a 66 unidades.

Os próximos gráficos complementam essas informações. Neles, é possível identificar todos os Institutos Federais do país com sua distribuição por regiões (gráfico 3) bem como o quantitativo das Unidades - ou campi - relacionados à cada Instituto (gráfico 4). Tomados em seu conjunto, os dados demonstram a forte presença no estado de São Paulo (38 unidades), ao mesmo tempo em que revela um esforço empreendido pelas políticas públicas federais no sentido da interiorização e distribuição no território. 
Gráfico 3 - Distribuição dos campi dos Institutos Federais por regiões brasileiras

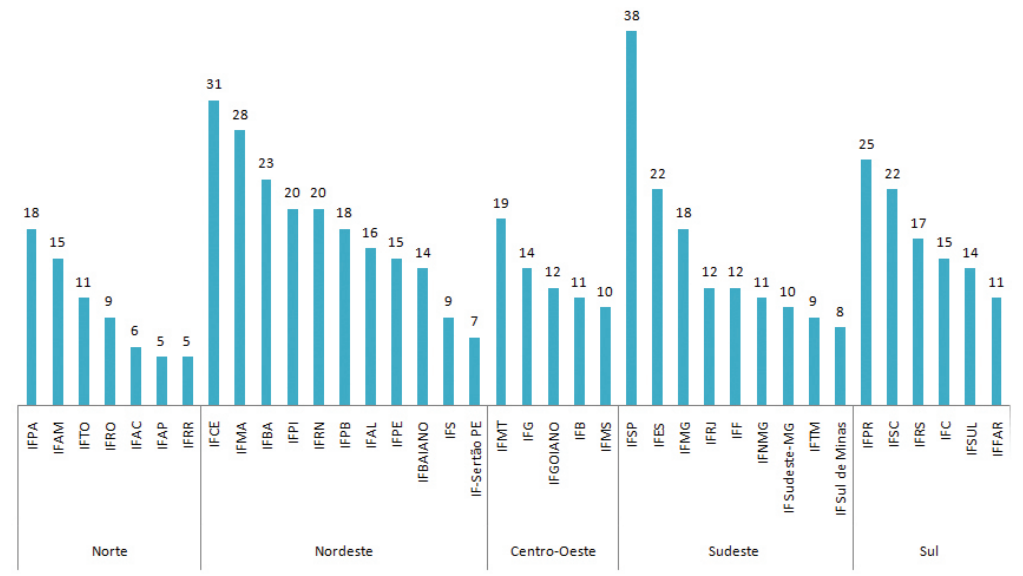

Fonte: Elaboração própria com base na Portaria n. ${ }^{\circ} 1.400$ de 05 de dezembro de 2016 (Brasil, 2016).

Gráfico 4 - Quantitativo dos campi dos Institutos Federais

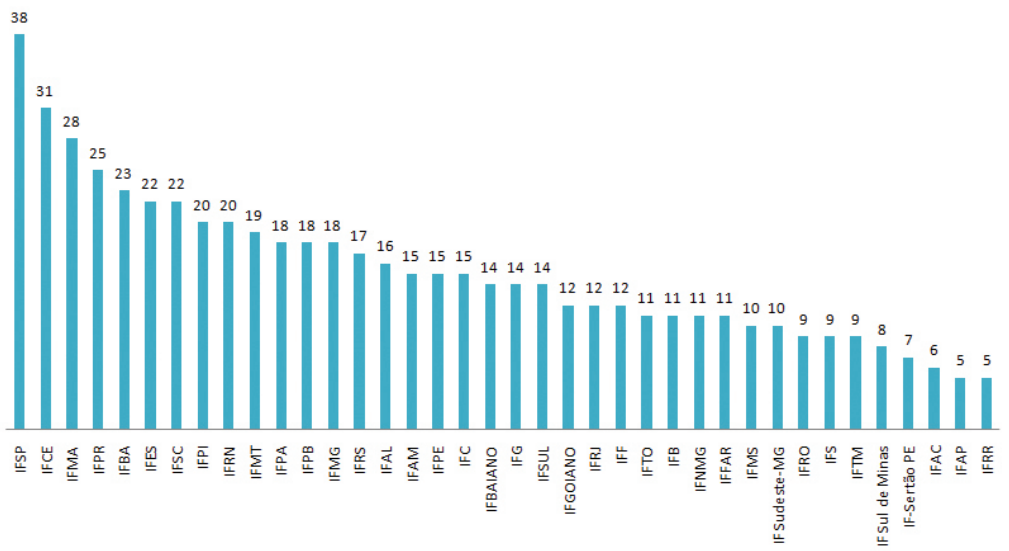

Fonte: Elaboração própria com base na Portaria n. ${ }^{0} 1.400$ de 05 de dezembro de 2016 (Brasil, 2016). 
Ao ser estendida para além das capitais, a rede de ensino profissional ganha maior capilaridade no território nacional, passando a alcançar municípios e regiões que, até então, não eram atendidos por essas instituições. Em termos concretos, isso se traduz num maior acesso das populações às políticas públicas educacionais voltadas à educação profissional de base técnica e tecnológica de nível médio e superior, bem como às licenciaturas em 11.264 cursos com mais de um milhão de matrículas. ${ }^{2}$

A constituição da RFEPCT teve como uma de suas "missões" centrais, contribuir com o desenvolvimento local e regional num processo de interiorização de suas unidades (Pacheco, 2011). No entanto, conforme argumentação de Lemos, Straforini e Teramatsu (2018)

[...] Há que se identificar as diferentes formas de inserção das instituições nas suas realidades locais-regionais de forma a problematizar essa associação direta Institutos/ universidades-desenvolvimento-território. Em outras palavras, há que se tensionar enunciados e pressupostos de forma a responder: qual tem sido o papel dos Institutos no desenvolvimento local? O que podem os Institutos? [...] Além disso, há um problema ou pano de fundo que nos parece central que é a não problematização dos pressupostos que fundamentam a proposta do próprio MEC/SETEC. Ou seja, há na concepção teórica - e política - que embasa essa proposta uma dupla supervalorização: por um lado, superestima a escala local no seu papel de deflagradora de processos de desenvolvimento e, por outro lado, dá excessivo valor ao papel de uma instituição de ensino nesse cenário (Lemos et al., 2018, p. 169).

${ }^{2}$ De acordo com dados do MEC e do Portal Nilo Peçanha. Disponível em: http:// redefederal.mec.gov.br/expansao-da-rede-federal e em https://www.plataformanilopecanha.org/. Acesso em: 25 fev. 2018. 
Mesmo tomando-se por pressuposto básico a importância e os efeitos positivos da maior presença dessas instituições no território nacional, há que se ressaltar que a mensuração dos seus efeitos e da abrangência econômica, social, cultural e política disso ainda se configura como um debate em aberto.

\section{As licenciaturas no âmbito da Rede Federal de Educação Profissional, Científica e Tecnológica}

As razóes das iniciativas governamentais no sentido de incorporar a formação de professores no interior da RFEPCT devem ser buscadas, primeiramente, num quadro mais amplo relativo à carência de profissionais ante a baixa atratividade - logo, de procura - que a carreira do magistério representa para os jovens postulantes ao ingresso nas universidades (Gatti et al., 2010). Tal desinteresse pela carreira docente se consubstancia numa tendência de diminuição no número de matrículas das licenciaturas (Gatti et al., 2011) e numa escassez de professores especialmente para as nas áreas de física, química, matemática e biologia (Brasil, 2007).

Impossível deixar de frisar que o cerne da questão não se situa exclusivamente na oferta de vagas e na abertura de oportunidades para a realização de cursos voltados ao magistério, mas na necessidade de valorização do trabalho do professor em aspectos que englobam questôes salariais, mas que, no entanto, não se restringem a esse fator: condições de trabalho, infraestrutura das instituições de ensino, carreira, formação, valorização social e profissional, conduta dos alunos e violência nas escolas. Tudo isso torna urgente a reversão desse quadro de forma a promover a atração e a permanência dos profissionais por meio de planos de carreira que sejam capazes de estimular "o interesse pela profissão docente, bem como a permanência nela” (Masson, 2017, p. 861). Para finalizar essa questão da maior oferta de cursos como uma resposta visando "resolver" o 
problema da falta de professor, citamos textualmente as palavras de Lima (2016), como forma de corroborar a posição aqui tomada:

Contudo, é possível afirmar que duas questões são fundamentais para compreender o cenário apontado: a desvalorização da profissão docente e as más condições de seu exercício, aspectos que precisam ser considerados de forma imperativa na formulação de políticas públicas destinadas ao campo. Nesse contexto, apenas as ações governamentais destinadas à criação de cursos ou programas de formação docente são insuficientes para o equacionamento da questão, pois não se defrontam com estes dois problemas centrais. A abertura de cursos pode ser ainda compreendida, erroneamente, como solução para a questão geral da escassez de profissionais na área, assim como podem falsamente naturalizar o problema, já que não aprofundam a discussão dos motivos que contribuem para a falta de docentes na educação básica (Lima: 2016, p. 185, grifos nossos).

Dito isso, chamamos a atenção para o fato de que, embora esse quadro de escassez e de desestímulo à carreira docente não seja uma exclusividade do Brasil, repetindo-se em outras partes (Imbernón, 2006; OECD, 2005), por aqui tal fato ainda é potencializado pela alta porcentagem de professores que, ou não possuem formação superior ou que a possuem, mas não na área específica das classes para as quais ministram aulas (Gatti, 2014). Segundo dados do Observatório do Plano Nacional de Educação (PNE) ${ }^{3}$ para o ano de 2017, 52,7\% dos professores dos anos finais da Educação Básica não possuem formação de nível superior específica na área que atuam. No Ensino Médio, ainda segundo o Observatório, nesse mesmo ano, 44,4\% dos docentes se encontravam, também, nessa situação.

3 Disponibilizado em www.observatoriodopne.org.br/metas-pne/15-formacao-professores 
Conforme se tem demonstrado aqui, o processo de formação e de consolidação legal dos Institutos se deu por meio de Decretos presidenciais editados ao longo dos anos 1990 e 2000 até a completa realização desse processo com a criação da RFEPCT em 2008 (Brasil, 1997; 2004; 2007 e 2008). A leitura dessa legislação, numa perspectiva diacrônica, revela o delinear da institucionalização de um modelo que agregaria diversas atribuições e objetivos dentro de uma mesma estrutura educacional, operada em rede pelo governo federal, no interior do qual a formação de professores passaria a ter um papel de relativa importância.

Se num primeiro momento falava-se no oferecimento de cursos de licenciatura, bem como de programas especiais de formação pedagógica nas áreas científicas e tecnológicas (Brasil, 1997 e 2004), a legislação passa a incluir, de forma explícita, a formação de professores para a Educação Básica, principalmente para as áreas de ciência e de matemática (Brasil, 2007 e 2008), o que atenderia àquelas demandas por professores nessas áreas. No entanto é com a Legislação que cria a RFEPCT (Lei n. ${ }^{\circ} 11.892 / 2008$, Art. $8^{\circ}$ ), que essa prerrogativa irá tomar vulto não só com a confirmação do lugar reservado às licenciaturas no interior dos Institutos como também com a determinação da necessidade de reserva de $20 \%$ das matrículas para essa formação. Os "Institutos Federais" tornam-se, assim, um novo lócus para a formação de professores no país constituindo-se em "novos espaços de formação" (Macedo, 2010).

A presente pesquisa procedeu a uma investigação detalhada dos cursos de licenciatura oferecidos na Rede tendo por base os dados disponibilizados na Plataforma Nilo Peçanha. O levantamento foi feito estabelecendo-se por parâmetros toda oferta de cursos de licenciaturas presenciais na RFEPCT. Os números mais gerais apontam um total de 611 cursos, distribuídos por 26 áreas e ofertados em 277 unidades de ensino em todo território nacional. 
Gráfico 5 - Licenciaturas (presenciais) nos Institutos Federais

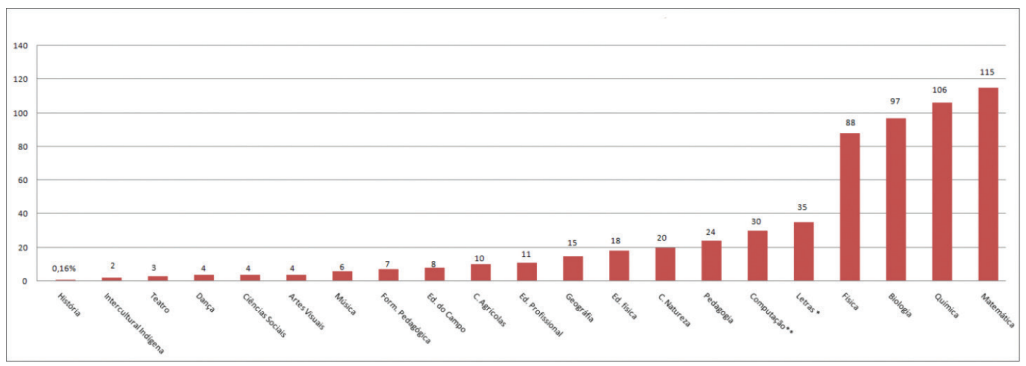

* Letras: Língua Portuguesa, Línguas Estrangeiras, Libras

** Computação: informática e computação

Fonte: Elaboração Própria com base nos dados da Plataforma Nilo Peçanha. Disponível em: https://www.plataformanilopecanha.org/.

Quatro áreas concentram quase 70\% da oferta de licenciaturas nos Institutos: Química (88 cursos), Matemática (86 cursos), Biologia (71 cursos) e Física (70 cursos) (Gráfico 5). Esse percentual é ainda maior se levarmos em consideração que Ciências da Natureza, com sete cursos, poderia ser acrescentado a esse cômputo. Conforme pode ser visto na nota explicativa no final do gráfico, trata-se de cursos nos quais o discente realiza uma trajetória formativa com uma parte comum ou um núcleo básico inicial e, só depois em algum momento do curso, opta pela habilitação justamente em Química, em Física ou em Biologia. De forma geral, é possível ao aluno ter mais de uma formação nessas áreas desde que cumpra as exigências de matrícula e as obrigações que lhes são exigidas de acordo com cada Projeto Político-Pedagógico de Curso.

Para além da tentativa de resposta à carência de profissionais nessas áreas, a prevalência de cursos de licenciatura nas áreas de Química, Matemática, Biologia e Física pode ser atribuída, em primeiro lugar, ao fato de se tratarem de componentes curriculares os quais os Institutos têm certa expertise e isso tanto no que se refere à existência de um corpo de professores disponível nessas áreas quanto em função do tradicional peso nos cursos de nível médio e técnico. 
De forma geral, o movimento em direção à criação dos cursos parece se originar nas coordenações de áreas, a partir do quadro de professores existente e da disponibilidade dos mesmos em iniciar as atividades dos cursos. Cabe chamar a atenção, então, que os cursos, de forma geral, se iniciam a partir de professores oriundos do ensino médio e técnico que empreendem um esforço em direção à construção de cursos superiores. A partir de um núcleo inicial de professores da área específica são agregados outros, de áreas afins, que passam, igualmente, a fazer parte dos cursos.

Além da existência desse núcleo básico de professores e do peso dessas disciplinas no currículo em geral das antigas Escolas Técnicas, contribui ainda para o predomínio dessas áreas a infraestrutura física de laboratórios existentes nos Institutos (muito superior às das escolas públicas estaduais e municipais e mesmo privadas), e a tradição em estudos e experimentações junto aos alunos e uma rotina de compra de materiais de consumo. Química ilustra bem esse quadro, tendo em vista a existência de cursos técnicos na área, laboratórios e professores experientes presentes nas instituições.

Os cursos de licenciatura na área profissional ocupam uma posição muito residual no cenário das licenciaturas nos Institutos. Um estudo anterior realizado por Araújo (2016) demonstrou que aproximadamente $65 \%$ das licenciaturas ofertadas na rede são nas áreas de Ciências e de Matemática, ao passo que a área de Educação Profissional abarca uma porcentagem muito pequena do total dos cursos (somente 3\%), "indicando uma menor atenção dada pela rede de educação profissional e tecnológica, aos cursos destinados a formar professores para a educação profissional" (Araújo, 2016, p. 48). Os dados da presente pesquisa se aproximam desses dados já que, enquanto Química, Matemática, Biologia e Física concentram quase $70 \%$ dos cursos, a formação profissional beira os $6 \%$.

Destaque pode ser dado aos cursos de Computação e de Informática (que foram agrupados na presente pesquisa): com 24 cursos espalhados pelo país (5,26\%), é a área que concentra a maior parte do 
reduzido número de licenciaturas na área profissional. Acreditamos que, similarmente ao curso de Química, trata-se de uma área com considerável peso na rede tanto no que se refere à presença de cursos técnicos, quanto à existência de professores e de laboratórios pré-existentes, o que explica, em parte, a sua presença, mas não o seu número reduzido no interior da RFEPCT, já que a possibilidade de oferta de cursos de formação de professores para as áreas profissionais foi sempre uma questão posta, não só como uma possibilidade ou prerrogativa, mas como uma necessidade expressa. No documento "A formação de educadores para a educação profissional”, encontramos a seguinte passagem, bastante elucidativa do que estamos tratando aqui:

Pensamos que é possível os Centros Federais se colocarem nessa tarefa de formação de formadores. Principalmente por terem implantado os cursos de licenciatura, torna-se bastante viável a elaboração de um itinerário de formação que possibilite que estudantes dos cursos superiores de formação de tecnólogos que desejaram ingressar na carreira docente, possam fazê-lo de forma articulada. Se antes, "os cursos emergenciais" ministrados por esses centros já trouxeram uma colaboração significativa para os professores considerados leigos, dessa forma ora proposta, as instituições estariam também trabalhando na superação desses cursos de capacitação pedagógica, além de estarem contribuindo mais eficazmente para formar professores para as disciplinas específicas dos cursos (MEC/ SETEC, 2004, p. 10).

Há a esse respeito um problema ou pano de fundo teórico mais geral relativo à insuficiência de uma discussão epistemológica mais aprofundada sobre os saberes docentes e pedagógicos da formação e

4 Regulado pela Resolução n. ${ }^{\circ}$ 02/1997 do CNE, os programas especiais de formação pedagógica para docentes do ensino fundamental médio e da educação profissional se dirigiam àqueles professores que eram portadores de diploma de nível superior, mas que não possuíam a formação pedagógica necessária ao exercício do magistério. 
da prática de professores para a educação profissional. A análise histórica das políticas de formação docente para a EPT revela o caráter fragmentário, descontínuo e indefinido com que essa formação tem sido tratada pelas políticas públicas educacionais no país (Carvalho e Souza, 2014; Urbanetz, 2012 e Vieira et al, 2014). O próprio caráter "especial" expresso na legislação, ${ }^{5}$ voltado para suprir a carência de professores habilitados em diversas áreas do ensino fundamental e médio e incluindo-se aí, de forma geral e indistinta, a educação profissional, revela o tratamento que essa área de formação tem recebido do poder público. Para Oliveira (2010, p. 461):

Isto tem a ver com uma dada concepção sobre as relações entre experiência profissional e formação acadêmica, permeada por um não reconhecimento da docência na EPT como um campo de conhecimento com identidade própria.

Essse pano de fundo, no entanto, não é suficiente para resolver o aparente paradoxo, a saber, o porquê de os Institutos Federais oferecerem nos seus quadros de matrículas e de cursos uma porcentagem tão baixa de licenciaturas voltadas para a EPT. Algumas explicações gerais podem ser dadas a esse respeito, embora assuma-se aqui a necessidade de estudos mais aprofundados.

Um ponto a ser levado em conta é a própria trajetória da formação dos professores que atuam na EPT no interior dos institutos num sistema que se retroalimenta continuamente: diante da dificuldade de

5 Resolução n. ${ }^{\circ}$ 2/1997 (Brasil, 1997) dispõe sobre os programas especiais de formação pedagógica para docentes da educação profissional de nível médio num contexto mais amplo de "falta nas escolas de professores habilitados" e, por isso, da necessidade de formação de professores em caráter especial para a docência para o ensino fundamental, médio e para a educação profissional. Ao definir diretrizes curriculares para a educação profissional técnica de nível médio, o Art. 40 da Resolução n. ${ }^{\circ}$ 6/ 2012 (MEC: 2012), por seu turno, assegura ao professor graduado, mas não licenciado, a possibilidade de ter reconhecido "seus saberes profissionais" por meio de cursos de pós-graduação lato sensu, da segunda licenciatura, ou por meio da certificação da experiência, dentre outras. 
contratação de profissionais para a atuação nessa área que tenham a licenciatura, os quadros profissionais dos institutos são formados por bacharéis de diversas áreas. Embora tenha havido medidas especiais de complementação pedagógica, a realidade é que os professores que atuam na EPT vêm de uma cultura do bacharelado e, como a construção de licenciaturas é realizada com base no corpo de professores de cada Instituto, de seus interesses, anseios e horizontes profissionais, depreendem-se daí uma primeira possibilidade de entendimento da questão da baixa oferta de licenciaturas na área profissional.

\section{A ação de forças de coesão e de dispersão no seio da Rede Federal de Educação Profissional}

Qualquer esforço de compreensão do significado e do papel social e educacional dos Institutos deve levar em conta a sua abrangência, não só geográfica como também de atribuições, de objetivos, de programas e de formatos educativos. Ao abarcar tantas frentes de trabalho, a Rede acaba enfrentando desafios no que se refere à gestão de processos internos de registro e acompanhamento acadêmico de alunos que estudam sob diferentes modalidades, diferentes formas de ingresso, programas e, às vezes, até mesmo, de diferentes sistemas avaliativos. Ademais, o caráter relativamente recente da estrutura organizacional instituída pela Lei de criação da Rede traz consigo uma série de questões referentes à gestão dos recursos financeiros e humanos e às rotinas administrativas de cada unidade e da rede como um todo.

No entanto, as tensões não se circunscrevem a esses problemas de gestão da nova estrutura administrativa. Ao formarem uma "rede", tais instituições são instigadas à construção de laços, vínculos e coesões em relação a um exterior, ou seja, entre as diversas unidades e organizações acadêmicas que compõem a própria RFEPCT. Ora, o processo de expansão dos Institutos não se deu somente por meio de um incremento do número de unidades, mas pela mudança de parte significativa das bases institucionais e legais que discipli- 
navam o funcionamento da educação profissional federal e que, a partir de então, passavam a funcionar como uma "Rede Federal de Educação Profissional, Científica e Tecnológica” (RFEPCT).

Antes de prosseguirmos, é necessário chamar-se a atenção para o fato de que a rede - retis - pressupõe um conjunto de linhas na qual cada "nó" corresponde aos pontos de sua intersecção. Mais especificamente, as redes geográficas se referem a grupos de localizações geográficas interconectadas entre si por meio de um conjunto de ligações, vias e fluxos (Corrêa, 2012 e Santos, 2004). A rede tem, portanto, uma dimensão material, concreta, referente às capacidades físicas instaladas com vistas a conectar áreas ou pontos (Gregory et al, 2009), a exemplo das redes de transporte e de comunicações (Dias, 1995). Mas a rede não se circunscreve a essa materialidade posto que simultaneamente seja marcada por relações sociais e políticas, "pelas pessoas, mensagens, valores que a freqüentam". Portanto, para Santos (2004, p. 262), “sem isso e a despeito da materialidade com que impõe aos nossos sentidos, a rede é, na verdade, uma mera abstração".

Trazendo esses elementos - en passant, é verdade - sobre redes em geografia, pretendemos refletir o que conecta, o que une os diversos pontos representados pelas instituições que compõem a RFEPCT. Com a Lei n. ${ }^{\circ} 11.8920$, instituiu-se um formato no qual, mantendo-se a ideia de autonomia didática e administrativa das autarquias federais, as identificou como instituições multicampi e pluricurriculares, reunidas sob o mesmo sistema federal de ensino, como a Rede Federal de Educação Profissional, Científica e Tecnológica, vinculada ao Ministério da Educação.

No entanto, há que se ter em mente o caráter extremamente diverso das instituições abrigadas sob o mesmo guarda-chuva da Rede Federal: do quase bicentenário Colégio Pedro II, com suas 14 unidades restritas à cidade do Rio de Janeiro, ao jovem Instituto Federal do Amapá, com cerca de uma década de existência e suas seis unidades. De estruturas educacionais voltadas principalmente para a Educação 
Infantil, Ensino Fundamental e Médio, como o próprio Pedro II, e Colégios ligados a universidades, como é o caso do Colégio Universitário-COLUN da Universidade Federal do Maranhão, que oferece ensino Fundamental, Médio e Técnico. De instituições de ensino agrícola ligados a universidades àquelas originalmente dedicadas a essa modalidade, mas que foram incorporados recentemente aos Institutos Federais, como o Campus Bom Jesus do Itabapoana, antigo Colégio Técnico Agrícola Ildefonso Bastos Borges (CTAIBB), ligado desde os anos 1970 à Universidade Federal Fluminense.

As diferenças internas à Rede podem ser compreendidas à luz da história de cada instituição: de um "núcleo" inicial no início do Século XX com a criação das Escolas e Aprendizes e Artífices as diversas instituições foram moldando suas formas de inserção às realidades locais e regionais e suas relações com o governo central pari passo ao estabelecimento de arranjos e negociações em face das contingências e contradições que permearam e permeiam as próprias realidades de suas comunidades internas. São reveladores, a esse respeito, os casos do CEFET-RJ e do CEFET-MG que decidiram não aderir ao processo de criação dos Institutos Federais em 2008, optando por continuarem como Centros Federais. Como vislumbre, a possibilidade de vir a trilhar o mesmo caminho do antigo CEFET-PR, atual Universidade Federal Tecnológica do Paraná (UFTPR). Esta, por sua vez, sempre representou um caso muito particular no contexto das antigas escolas do início do Século XX, tendo "saltado" diretamente de CEFET para Universidade sem ter se tornado Instituto Federal. Além disso, hoje, a UFTPR sequer está ligada à SETEC ou ao CONIF (apesar de, oficialmente, fazer parte da RFEPCT).

Nesse contexto, destacam-se como elemento de coesão da Rede o seu papel na implementação de políticas e diretrizes emanadas do Ministério da Educação (MEC) e da Secretaria de Educação Profissional e Tecnológica (SETEC). Tendo esta Secretaria o papel de criação, manutenção e supervisão da RFEPCT e concatenando, nacionalmente, as ações relacionadas à educação profissional, esta 
acaba por constituir-se na instância federal com um papel centralizador de diretrizes, às quais a rede deve se relacionar e se reportar diretamente.

Por outro lado, ainda como elemento aglutinador, destaca-se a criação e consolidação do que chamaremos aqui de instância supra-institucional, representada pelo Conselho Nacional das Instituições da Rede Federal de Educação Profissional, Científica e Tecnológica, o CONIF. Seu papel pode ser compreendido, a meu ver, como órgão que atua em relação a atores como o próprio governo e outras instituições de ensino, no sentido da "valorização e defesa" das instituições que fazem parte dessa organização. A partir de demandas concernentes, por exemplo, à garantia de verbas orçamentárias públicas que são (ou que deveriam ser) destinadas à rede, ou ainda por meio do reforço, defesa e garantia do papel das instituições como lócus de produção de conhecimento e formação de profissionais. Em suma, o CONIF advoga estratégias para a defesa dos interesses das Instituições ante as esferas governamentais do Poder Executivo bem como ante a sociedade no sentido de garantia do papel da RFEPCT no cenário educacional brasileiro. Como lócus de discussões, planejamentos e ações, o CONIF contribui para a criação de um esprit de corps que permeia a rede.

\section{Considerações finais}

A RFPCT é formada por um conjunto de instituições públicas federais que oferecem mais de 11 mil cursos a cerca de um milhão de estudantes espalhados pelo país. ${ }^{66}$ Trata-se de instituições que, mesmo aquelas mais jovens, estão solidamente enraizadas às suas realidades locais e regionais e que - ousaríamos dizer - gozam do reconhecimento da sociedade pelo ensino público que oferecem, pela boa for-

$6{ }^{6}$ Os números exatos disponibilizados pela Plataforma Nilo Peçanha são 11.264 cursos e 1.031.798 matrículas. 
mação de seus professores e pela infraestrutura física e de pessoal de suas instalações.

Ao selecionar certos marcos da trajetória da constituição da Rede e ao trazer elementos da legislação que regula a atuação dessas instituições, o artigo procurou oferecer elementos visando à melhor compreensão da distribuição da Rede no território brasileiro, dando destaque às licenciaturas, bem como aos desafios postos ao seu processo de consolidação em curso.

Enquanto "rede", os Institutos Federais enfrentam atualmente desafios e forças que atuam tanto como elementos de coesão como de dispersão. A grande questão é descobrir até que ponto tal variedade de situações pode exercer o papel de força centrífuga, de centralização, ou centrípeta, de pulverização, no seio da própria rede.

\section{Referências}

ANDRADE, A. DE F. B. Os Institutos Federais de Educação, Ciência e Tecnologia: uma análise de sua institucionalidade. (Tese). Brasília: Universidade de Brasília, 2014.

ARAÚJO, W. S. DE. Das Escolas Técnicas Federais aos Institutos Federais: a licenciatura em física no campus Goiânia do IFG. (Dissertação). Goiânia: Universidade Federal de Goiás, 2016.

BRASIL. Decreto N. ${ }^{\circ} 7.566$, de 23 de setembro de 1909. Disponível em: http:// portal.mec.gov.br/setec/arquivos/pdf3/decreto_7566_1909.pdf. Acesso em: 22 nov. 2017.

. Lei N. ${ }^{\circ} 6.545$, de 30 de junho de 1978. Disponível em: http://www2. camara.leg.br/legin/fed/lei/1970-1979/lei-6545-30-junho-1978-366492-normaatualizada-pl.pdf. Acesso em: 18 jan. 2018.

. Lei N. ${ }^{\circ} 7.863$, de 31 de outubro de 1989. Disponível em: www.planalto. gov.br/ccivil_03/leis/1989_1994/L7863.htm. Acesso em: 04 de maio de 2018. 
. Lei N. 8.711 , de 28 de setembro de 1993. Disponível em: http://www. planalto.gov.br/ccivil_03/leis/1989_1994/L8711.htm. Acesso em: 22 nov. de 2017.

. Lei N.o 8.948, de 8 de dezembro de 1994. Disponível em: http://www. planalto.gov.br/ccivil_03/leis/L8948.htm. Acesso em: 22 nov. 2017.

. Decreto 2.208, de 17 de abril de 1997. Disponível em: www.planalto.gov. br/ccivil_03/decreto/D2208.htmimpressa.htm. Acesso em: 18 jan. 2018.

. Decreto N. ${ }^{\circ} 5.224$ de $1^{\circ}$ de outubro de 2004. Disponível em: http:// www.planalto.gov.br/ccivil_03/_ato2004-2006/2004/decreto/d5224.htm. Acesso em: $15 \mathrm{dez} .2017$.

. Decreto N. ${ }^{\circ} 5.800$, de 8 de junho de 2006. Disponível em: http://www2. camara.leg.br/legin/fed/decret/2006/decreto-5800-8-junho-2006-543167-publicacaooriginal-53181-pe.htm. Acesso em: 18 jan. 2018.

. Lei N. ${ }^{\circ} 11.892$, de 29 de dezembro de 2008. Disponível em: http://www. planalto.gov.br/ccivil_03/_ato2007-2010/2008/lei/111892.htm. Acesso em: 18 jan. 2018.

. "Um novo modelo em Educação Profissional e Tecnológica”. Concepção e Diretrizes. Ministério da Educação, 2010. Disponível em: http://portal.mec. gov.br/index.php?option $=$ com_docman\&view $=$ download\&alias $=6691$-if-concepcaoediretrizes\&Itemid=30192 Acesso em: 03 fev. 2018.

. MINISTÉRIO DA EDUCAÇÃO. Escassez de professores no Ensino Médio: propostas estruturais e emergenciais. Ministério da Educação: Brasília, 2007. Disponível em: http://portal.mec.gov.br/cne/arquivos/pdf/escassez1. pdf. Acesso em: 15 dez. 2017.

. "Portaria N. 1.400 de 05 de dezembro de 2016". Diário Oficial da União. Brasília, 06 dez. 2016.

. SECRETARIA DE EDUCAÇÃO PROFISSIONAL E TECNOLÓGICA (SETEC). "A formação de professores para a educação profissional". Fórum de Educação Profissional. Brasilia, 2004. Disponível em: http://portal. mec.gov.br/setec/arquivos/pdf/Texto_apresenta01.pdf. Acesso em: 30 out. 2018. 
. Lei $N^{\circ} 12.513$, de 26 de outubro de 2011a. Disponível em: http://www. planalto.gov.br/ccivil_03/_ato2011-2014/2011/lei/112513.htm. Acesso em: 23 de Nov. de 2017.

Portaria $N^{o} 1.015$, de 21 de julho de 2011b. Disponível em: http://portal.mec. gov.br/index.php?option=com_docman\&view=download\&alias=8589-portaria1015-220711-pmm-pdf\&category_slug=agosto-2011-pdf\&Itemid=30192. Acesso em: 23 nov. 2017.

CARVALHO, O. F. DE e SOUZA, F. H. DE M. "Formação do docente da educação profissional e tecnológica no Brasil: um diálogo com as faculdades de educação e o curso de pedagogia”. Educ. Soc., Campinas, v. 35, n. 128, pp. 629-982, jul.-set. 2014.

CORRÊA, R. L. "Redes geográficas: reflexões sobre um tema persistente". Cidades, v. 9, n. 16, pp. 199-218, 2012.

FARTES, V. L. B. "A cultura profissional dos grupos de pesquisa nos Institutos Federais: uma comunidade de práticas?". Cadernos de Pesquisa, v. 54, n. 154, pp. 850-74, out.-dez. 2014.

FREITAS, A. S. F. et al. "As dimensões territorial e política do Programa Institucional de Bolsa de Iniciação à Docência (PIBID)". Revista Terra Livre, v. 1, pp. 75-113, 2015.

GATTI, B. et al. Politicas Docentes no Brasil: um estado da arte. Brasília: Unesco, 2011.

. "A atratividade da carreira docente no Brasil". Estudos \& Pesquisas Educacionais, São Paulo, n. 1, maio 2010.

. "A Formação inicial de professores para a Educação Básica: pesquisas e políticas educacionais”. Est. Aval. Educ. São Paulo, v. 25, jan.-abr de 2014.

GOUVEIA, F. P. DE S. e SILVA, K. C. "A impossibilidade da construção da identidade dos Institutos Federais de Educação, Ciência e Tecnologia sob a égide da pequena política". In IV Colóquio Nacional e I Colóquio Internacional A produção do conhecimento da Educação Profissional. Anais... Natal (RN), 24-27 julho de 2017. pp. 1-14.

GREGORY, D. et al. "Network(s)". In: The Dictionary of human Geography. Wiley-Blackwell. Padstow/Cornwall, 2009. pp. 498-99. 
IMBERNÓN, F. "La profesión docente desde el punto de vista internacional: que dicen los informes?". Revista de Educación, n. 340, p. 41-49, 2006.

KUNZE, N. C. "O surgimento da rede federal de educação profissional nos primórdios do regime republicano brasileiro". Revista Brasileira de Educação Profissional e Tecnológica. Brasília: Ministério da Educação/Secretaria de Educação Profissional e Tecnológica, v. 2, n.2, nov. 2009, pp. 8-24.

LIMA, M. F. B. “A expansão dos cursos de licenciatura nos Institutos Federais de Educação, Ciência e Tecnologia: considerações sobre a proposta governamental". In: XXIV Seminário Nacional UNIVERSITAS/BR. Universidade Estadual de Maringá - Anais... 18-20 maio 2016. pp. 169-88.

LEMOS, L. M. et al. "Os Institutos Federais de Educação e seu sentido discursivo provisório de desenvolvimento local-regional”. In: 5. ${ }^{\circ}$ Colóquio Internacional da Rede Latino-Americana de Investigadores de Didática da Geografia (REDLADGEO). Anais... Goiânia/Pirinópolis, 2018. pp.160-72.

MACEDO, J. M. "Formação de professores em nível superior no Brasil: os caminhos da inclusão excludente". RETTA (Revista em Educação Técnica e Tecnológica em Ciências Agrícolas), v. 1, n. 2, pp. 69-83, jul.-dez. 2010.

MASSON, G. Requisitos essenciais para a atratividade e a permanência na carreira docente. Educ. Soc., Campinas, v. 38, no. 140, pp. 849-64, jul.-set., 2017.

OECD (Organisation for Economic Co-operation and Development). Teachers Matter: attracting, developing and retaining effective teachers, 2005. Disponível em: https://www.oecd.org/edu/school/34990905.pdf. Acesso em: 30 out. 2016.

OLIVEIRA, M.R.N.S. DE. "A formação de professores para a educação profissional”. In: DALBEN, A.L. et al (orgs.). Coleção Didática e Prática de Ensino. Belo Horizonte: Autêntica, 2010. pp. 454-78.

PACHECO, E. (Org.). Institutos Federais, uma revolução na Educação Profissional e Tecnológica. São Paulo: Moderna, Brasília: Fundação Santillana, 2011.

PEREIRA, L. A. C. A Rede Federal de Educação Tecnológica e o desenvolvimento local. 2003. (Dissertação). Campos dos Goytacazes: Universidade Cândido Mendes, 2003. 
- A formação de educadores para a educação profissional. Ministério da Educação e Cultura: Brasília, Ago. 2004. Disponível em: http://portal.mec. gov.br/setec/arquivos/pdf/Texto_apresenta01.pdf. Acesso em: 19 dez. 2017.

QUEVEDO, M. DE. Verticalização nos Institutos Federais de Educação, Ciência e Tecnologia: concep̧̧ão (ões) e desafios no IFRS. (Dissertação). Porto Alegre: Universidade Federal do Rio Grande do Sul, 2016.

SANTOS, M. A natureza do espaço. São Paulo, Edusp, 2004.

SILVA, E. P. DA. Limites epossibilidades de contribuição aos processos de integração regional, desenvolvimento local c combate às desigualdades pelo Instituto Federal de Educação, Ciência e Tecnologia. (Tese). São Leopoldo: Universidade do Vale dos Sinos/UNISINOS, 2016.

SOARES, M. de J. A. "As Escolas de Aprendizes Artífices - estrutura e evolução". Rio de Janeiro, Revista Forum Educacional, n. 6, v. 2, pp. 58-92. jul.-set.1982.

URBANETZ, S. T. "Uma ilustre desconhecida: a formação docente para a educação profissional”. Rev. Diálogo Educ., Curitiba, v. 12, n. 37, pp. 863-83, set.-dez. 2012.

VIEIRA, M. M. M. et al. "Formação de professores da educação profissional nos programas especiais de formação pedagógica”. Revista Brasileira da Educação Profissional Tecnológica. n. 7, v. 1, 2014, pp. 43-55.

WEINBERG, P. D. "A construção de uma nova institucionalidade para a formação”. Boletim Técnico do Senac, n. 30, v. 3, Rio de Janeiro, set.-dez. 2001, pp. 30-45. 